\title{
Initial Ca 125 Value as a Predictive Marker for High-grade Serous Ovarian Cancer
}

\author{
Seval Ay ${ }^{1}$, Deniz Tataroglu Ozyukseler ${ }^{2}$, Ozgecan Dulgar ${ }^{1}$, Mustafa Basak ${ }^{2}$, Mahmut Emre Yildirim ${ }^{2}$ and Mahmut \\ Gumus $^{1}$ \\ ${ }^{1}$ Department of Medical Oncology, Istanbul Medeniyet University, Goztepe Education and Research Hospital, Istanbul, Turkey \\ ${ }^{2}$ Department of Medical Oncology, Kartal Lutfi Kirdar Education and Research Hospital, Istanbul, Turkey
}

\begin{abstract}
Objective: To determine the relevance between the cut-off level of cancer antigen 125 (CA 125) level and long-term prognosis in high-grade serous ovarian cancer (HGSCS).

Study Design: Observational study.

Place and Duration of Study: Departments of Oncology, Medeniyet University Goztepe Education and Research Hospital, and Kartal Lutfi Kirdar Education and Research Hospital, Istanbul, Turkey, from January 2017 to June 2019.

Methodology: Medical records of 230 women with HGSC were reviewed randomly from two Oncology Clinics. Descriptive analysis and CA 125 marker levels were evaluated with five years of disease-free survival rate (DFS) and overall survival rate (OS). Patients were divided into groups of high and low initial CA 125 levels (cut-off $\geq 385 \mathrm{U} / \mathrm{ml}$ ). The ability of initial serum CA 125 levels in predicting the presence of marker-recurrence of ovarian cancer were analysed using ROC (Receiver operating characteristics) curve analysis.

Results: Statistically significant predictive value of initial CA 125 level was calculated as $385 \mathrm{U} / \mathrm{ml}(p=0.008)$. The 5 -year DFS of high and low CA 125 levels for all stages in HGSC was statistically significant $(p<0.001)$. The sub-group analysis demonstrated that the significant survival difference was especially in FIGO stage III. Patients with HGSC $<385 \mathrm{U} / \mathrm{ml}$ had a significantly improved 5-year DFS and OS rates within stage III disease: 5-year DFS $(p=0.008)$ and 5-year OS $(p=0.004)$ according to the stratification of CA 125 level.
\end{abstract}

Conclusion: Initial CA 125 level appeared to be of beneficial clinical predictive value for HGSC.

Key Words: Initial CA 125, Tumor marker, High-grade serous ovarian cancer, Disease-free survival, Overall survival, Predictive value.

How to cite this article: Ay S, Ozyukseler DT, Dulgar O, Basak M, Yildirim ME, Gumus M. Initial Ca 125 Value as a Predictive Marker for High-grade Serous Ovarian Cancer. J Coll Physicians Surg Pak 2021; 31(06):651-656.

\section{INTRODUCTION}

Ovarian cancer is the fifth most common cancer in women. ${ }^{1}$ Despite optimal surgical cytoreduction and new therapeutic agents, still the fifth most common cause of cancer related death in women. ${ }^{2}$ Unfortunately, five-year survival rates are below $30 \%$; foremost reason is the late diagnosis of ovarian cancer. ${ }^{2,3}$ Ovarian cancers are divided into epithelial and nonepithelial tumors, and 90 percent of ovarian cancers arise from ovarian epithelium. Epithelial ovarian cancer is also subdivided into four main histological subtypes: serous, endometrioid, mucinous, and clearcell. ${ }^{4}$

Correspondence to: Dr. Seval Ay, Department of Medical Oncology, Istanbul Medeniyet University, Goztepe Education and Research Hospital, Istanbul

E-mail:drsevalay@gmail.com

Received: December 15, 2020; Revised: April 16, 2021; Accepted: May 18, 2021

DOI: https://doi.org/10.29271/jcpsp.2021.06.651
The serous subtype is further classified as low-grade serous ovarian cancer (LGSC) and high-grade serous ovarian cancer (HGSC) based on pathological and clinical features. HGSC characterised by an aggressive course and a high probability of disease recurrence. ${ }^{4,5}$

Cancer antigen 125 (CA 125), a transmembrane glycoprotein, is major component of mucus protecting lining surface of organs from pathogens and is encoded by the homonymous MUC16 gene. ${ }^{6} \mathrm{CA}$ 125 is the most studied and validated biomarker in epithelial ovarian cancers and a well-established marker to follow-up patients that are diagnosed and treated with HGSCs. CA 125 has clinical limitations; increased values upper than cut-off levels are also associated with benign conditions. It is also raised in endometriosis, pelvic inflammatory conditions, normal physiological menstruation, pregnancy period, peritonitis and previous abdominal surgery. ${ }^{7,8} \mathrm{CA} 125$ levels are often used to evaluate treatment response in patients diagnosed with epithelial ovarian cancer especially HGSC. ${ }^{9,10}$ Previous studies have investigated the significance of CA 125 level at the time of diagnosis. ${ }^{11-13}$ Those studies showed that CA 125 levels were predictive of survival among patients with epithelial ovarian cancer, but outcomes are still unclear. 
The aim of this study was to evaluate predictive value of initial CA 125 level for women diagnosed with HGSC.

\section{METHODOLOGY}

The databases of the Medical Oncology Departments, Medeniyet University Goztepe Education and Research Hospital, and Kartal Lutfi Kirdar Education and Research Hospital, were used to study all patients diagnosed with ovarian cancer. All those patients were included who had undergone primary optimal resection for HGSC; and confirmed pathological stage according to FIGO (the International Federation of Obstetrics and Gynecology) staging system. ${ }^{14}$ Demographic characteristics studied were age at diagnosis, body mass index (BMI), marital status, number of childbirths, and menopausal status. Three hundred and ninety-four patients were found in the database; after analysing the medical records, 230 patients were chosen according to the following inclusion criteria: patients with histologic documentation of HGSC and patients with confirmed pathologicalstage I to III afteroptimal cytoreductive surgery. Those with normal CA 125 levels before surgery, age under 18 years, having more than one solid or hematologic tumor history, stage IV disease according to FIGO at the time of the diagnosis and patients with unresectable peritoneal or nodal disease were excluded. CA 125 levels were performed at Hospital. The CA 125 level was measured using the ARCHITECT system (Abbott Diagnostics). CA 125 values were documented within 3 weeks at initial diagnosis before surgery. The upper limit of normal value for CA 125 was $35 \mathrm{U} / \mathrm{ml}$ in both laboratories. ${ }^{15}$

Qualitative variables were expressed as count and percentage, while the quantitative variables were expressed as, minimum, and maximum. Receiver operating characteristic (ROC) curve analysis was performed to predict the cut-off value for the risk of recurrence of HGSC. To compare the area under the curve (AUC) between ROC curves, pairwise comparison analyses were used. Relation between survival data analysis and cut-off value of CA 125 level was performed. Survival analyses were performed using Kaplan-Meier method. Disease-free survival (DFS) was calculated from the date of HGSC diagnosis to the time of proven recurrence. Overall survival (OS) was calculated from the date of HGSC diagnosis until the time of death from any cause or the last follow up visit. Five-year DFS and OS were estimated using the Kaplan-Meier method. Initial CA 125 level was divided into two groups ( $<385 \mathrm{U} / \mathrm{ml} \mathrm{vs} . \geq 385 \mathrm{U} / \mathrm{ml}$ ) and was evaluated as a predictive value for OS and DFS in Cox regression analysis with and without risk-adjustment for age, body mass index (BMI), number of childbirths and menopause status. The reported $p$-values were two-sided, and $p$-value $<0.05$ was considered statistically significant. All data were analysed using SPSS statistical software version 17.0 (SPSS Inc, Chicago, IL, USA).

\section{RESULTS}

Medical records of 230 patients with HGSC were analyzed. The medianagewas $55.5(19-84)$ years; $66.5 \%$ of patients were post- menopausal, and $33.5 \%$ were premenopausal. Thirty percent of the patients were single or divorced, and $70 \%$ were married; $32.6 \%$ of the patients had BMI of $<25$ and $67.4 \%$ were $\geq 25$. One hundred and six (46.1\%) patients were FIGO stage I-II, and 124 patients (53.9\%) were FIGO stage III. In the follow-up, 98 patients were with recurrence of disease. In subgroup analysis, 79 patients $(80.6 \%)$ were diagnosed in FIGO stage III and 19 patients (19.6\%) were in FIGO stage I- II. In addition, 37 patients' deaths during follow up; 28 patients $(78.4 \%)$ in FIGO stage III and eight patients (21.6\%) were in FIGO stage I-II. The patients' demographic characteristics are summarised in Table I.

Table I: Clinicopathological characteristics of high-grade serous ovarian cancer.

\begin{tabular}{|c|c|c|}
\hline Characteristics & No. & $\%$ \\
\hline Median age in years (range) & $55.5(19-84)$ & \\
\hline$\leq 50$ & 85 & 37.0 \\
\hline$>50$ & 145 & 63.0 \\
\hline \multicolumn{3}{|l|}{ BMI $\mathrm{Kg} / \mathrm{m}^{2}$} \\
\hline$<25$ & 75 & 32.6 \\
\hline$\geq 25$ & 155 & 67.4 \\
\hline \multicolumn{3}{|l|}{ No. of childbirths } \\
\hline$\leq 2$ & 114 & 49.6 \\
\hline$>2$ & 116 & 50.4 \\
\hline \multicolumn{3}{|l|}{ Marital Status } \\
\hline Single & 69 & 30.0 \\
\hline Married & 161 & 70.0 \\
\hline \multicolumn{3}{|l|}{ FIGO } \\
\hline Stage $1-2$ & 106 & 46.1 \\
\hline Stage 3 & 124 & 53.9 \\
\hline \multicolumn{3}{|l|}{ Menopausal status } \\
\hline Postmenopausal & 153 & 66.5 \\
\hline Premenopausal & 77 & 33.5 \\
\hline \multicolumn{3}{|l|}{ Lymph node } \\
\hline Positive & 66 & 28.7 \\
\hline Negative & 164 & 71.3 \\
\hline
\end{tabular}

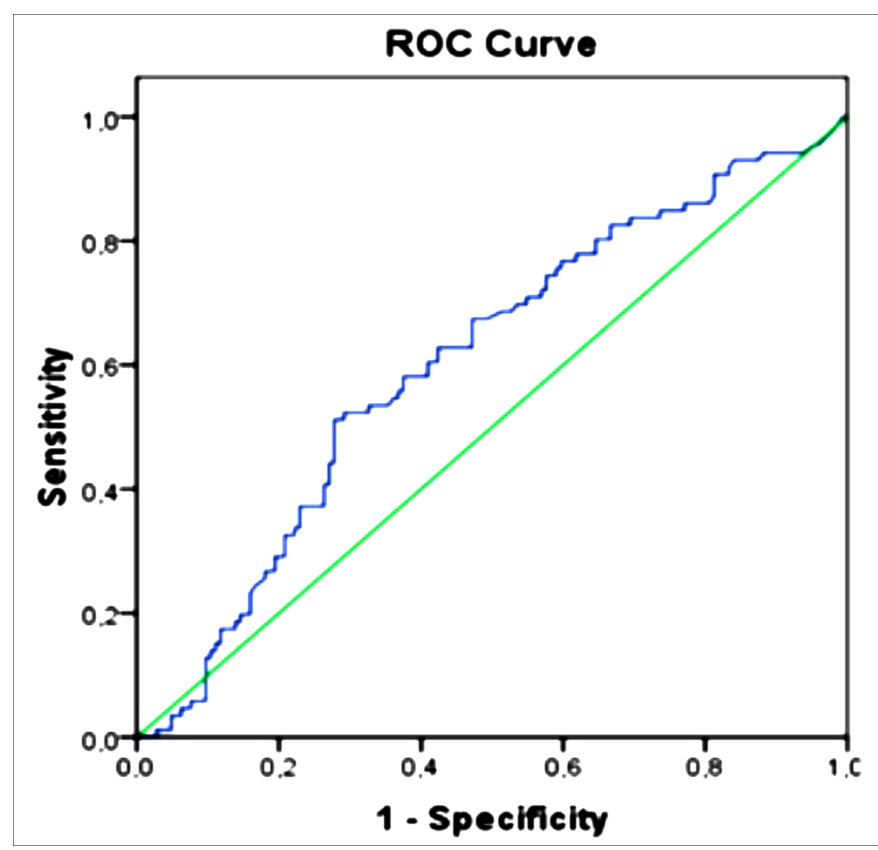

Figure 1: Receiver operating characteristic curve analysis. Representing of area under the curve curve $=0.605(p=0.008)$. 
Table II: Adjusted HRs and $95 \%$ Cls for 5-year OS and DFS by stage.

\begin{tabular}{|c|c|c|c|c|c|c|}
\hline \multirow{2}{*}{ Analysis types } & \multicolumn{6}{|c|}{ All stages combined $(n=230)$ Stage III $(n=124)$} \\
\hline & HR & $95 \% \mathrm{Cl}$ & $\mathbf{P}$ & HR & $95 \% \mathrm{Cl}$ & $\mathbf{P}$ \\
\hline \multicolumn{7}{|l|}{ Unadjusted (OS) } \\
\hline CA $125(\mathrm{U} / \mathrm{mL})<385$ & 1.00 & & 0.001 & 1.00 & & 0.008 \\
\hline CA $125(\mathrm{U} / \mathrm{mL}) \geq 385$ & 3.06 & $1.50-6.24$ & 3.75 & $1.41-9.97$ & & \\
\hline \multicolumn{7}{|c|}{ Adjusted for all covariates* (OS) } \\
\hline CA $125(\mathrm{U} / \mathrm{mL})<385$ & 1.00 & & 0.002 & 1.00 & & 0.010 \\
\hline CA $125(\mathrm{U} / \mathrm{mL}) \geq 385$ & 3.13 & $1.53-6.41$ & 3.73 & $1.38-10.14$ & & \\
\hline \multicolumn{7}{|l|}{ Unadjusted (DFS) } \\
\hline CA $125(\mathrm{U} / \mathrm{mL})<385$ & 1.00 & & $<0.001$ & & & 0.011 \\
\hline CA $125(\mathrm{U} / \mathrm{mL}) \geq 385$ & 2.23 & $1.45-3.42$ & $1.22-2.62$ & & & \\
\hline \multicolumn{7}{|c|}{ Adjusted for all covariates* (DFS) } \\
\hline CA $125(\mathrm{U} / \mathrm{mL})<385$ & 1.00 & & $<0.001$ & & & 0.076 \\
\hline CA $125(\mathrm{U} / \mathrm{mL}) \geq 385$ & 2.26 & $1.47-3.49$ & $0.95-2.54$ & & & \\
\hline
\end{tabular}

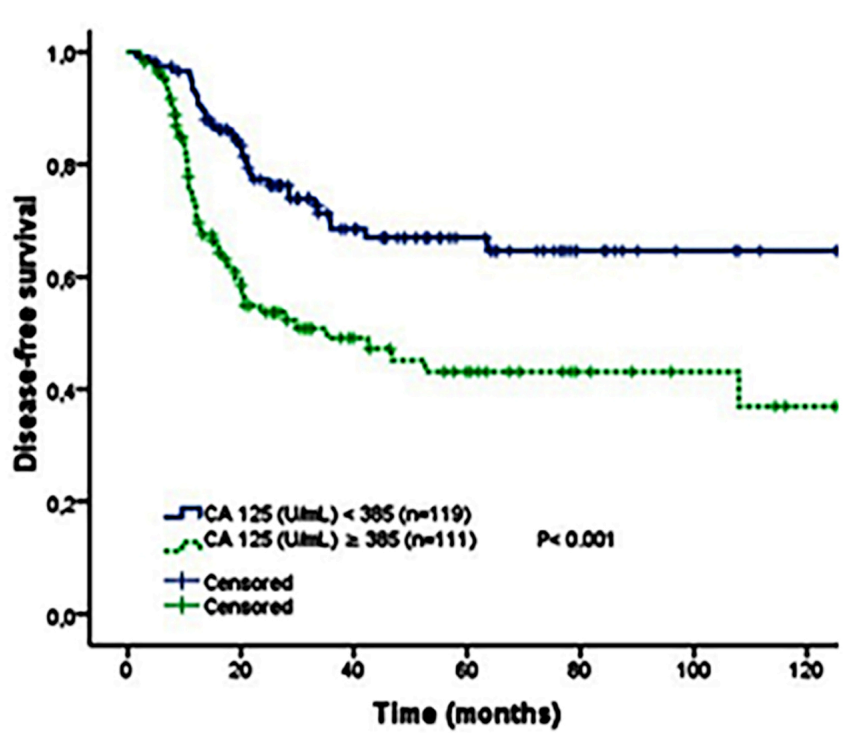

Figure 2: Kaplan-Meier curve of disease-free survival by initial CA 125 cutoff value for all FIGO stages of high-grade serous ovarian cancer patients ( $<385 \mathrm{U} / \mathrm{ml}$ vs. $\geq 385 \mathrm{U} / \mathrm{ml}$ ).

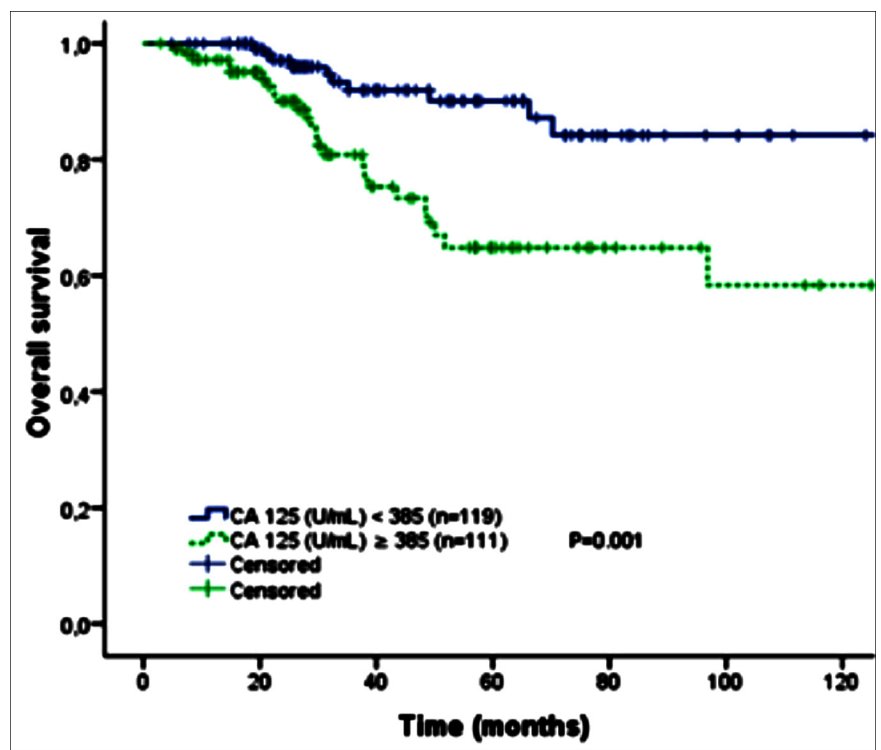

Figure 3: Kaplan-Meier curve of overall survival by initial CA 125 cutoff value for all FIGO stages of high-grade serous ovarian cancer patients $(<385 \mathrm{U} / \mathrm{ml} \mathrm{vs} . \geq 385 \mathrm{U} / \mathrm{ml})$.

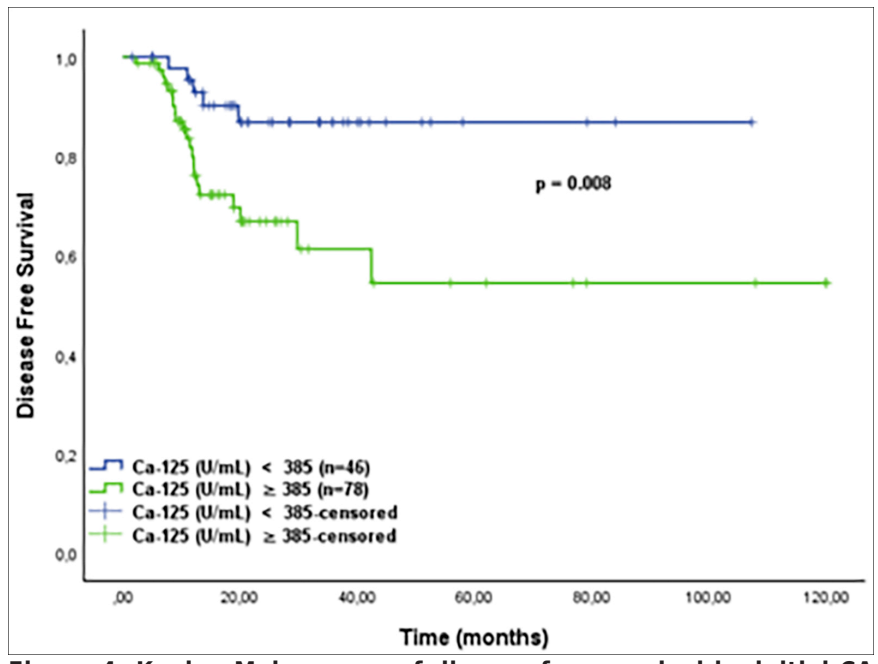

Figure 4: Kaplan-Meier curve of disease-free survival by initial CA 125 cut-off value for patients with FIGO stage III of high-grade serous ovarian cancer patients (<385 U/ml vs. $\geq 385 \mathrm{U} / \mathrm{ml}$ ).

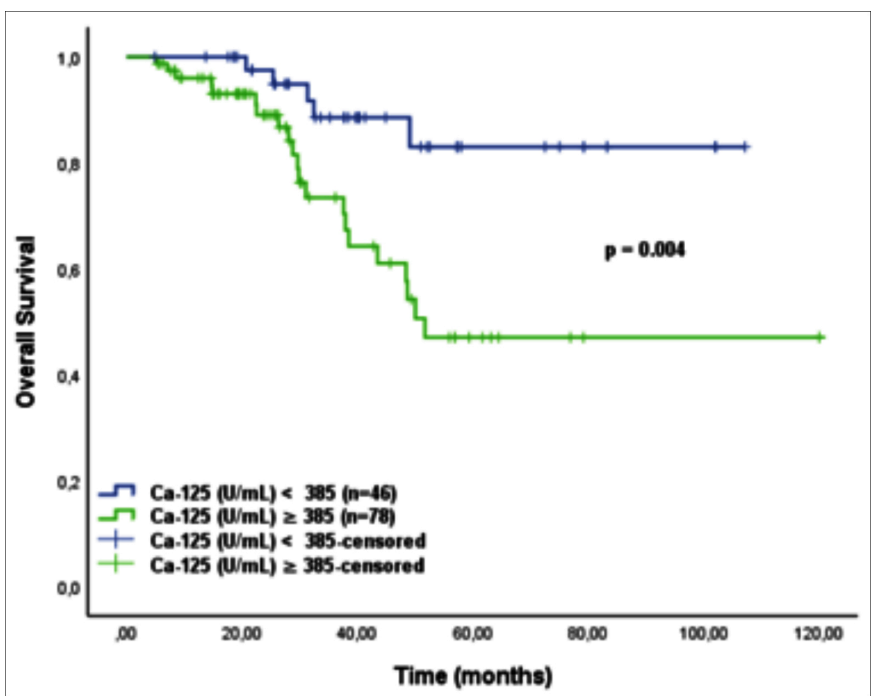

Figure 5: Kaplan-Meier curve of overall survival by initial CA 125 cutoff value for patients with FIGO stage III of high-grade serous ovarian cancer patients ( $<385 \mathrm{U} / \mathrm{ml}$ vs. $\geq 385 \mathrm{U} / \mathrm{ml}$ ).

Among the 230 patients, 210 patients (91.3\%) received adjuvant chemotherapy, while 20 patients $(8.7 \%)$ only had 
surgery without adjuvant chemotherapy. One hundred and eighty-eight $(81.7 \%)$ patients had received 4 or more cycles; $42(18.3 \%)$ had received less than 4 cycles. Patients received neoadjuvant chemotherapy before surgery were excluded.

The ability of initial serum CA125 level in predicting presence of recurrence of ovarian cancer was analysed using ROC (Receiver operating characteristics) curve analysis. In this study statistically significant predictive value of initial CA125 level was calculated '385' $\mathrm{U} / \mathrm{ml}(\mathrm{p}=0.008)$ with sensitivity (60.5\%) and specificity (59\%), with corresponding AUC of 0.605 (95\% C.I: 0.529-0.680, $p=0.008$ ). Details are shown in Figure 1.

Five-year disease-free survival and overall survival were estimated using the Kaplan-Meier method. The difference if effect of different factors were determined by Log-rank test. Median CA 125 level in all stages was $390 \mathrm{U} / \mathrm{ml}$; in FIGO stage III was $433 \mathrm{U} / \mathrm{ml}$. Patients were divided into groups of high and low initial CA 125 levels (cut-off $\geq 385 \mathrm{U} / \mathrm{ml}$ ). The 5 -year DFS of high and low CA 125 levels for all stages in HGSC was statistically significant $(p<0.001)$, (Figure 2$)$. Moreover, there was a significant difference in the 5-year OS between the two groups ( $p=0.001$, Figure 3 ). Details for all stages are shown in Table II.

The sub-group analysis demonstrated that the significant survival difference was seen in FIGO stage III. Patients with HGSC with CA 125 level below $385 \mathrm{U} / \mathrm{ml}$ had a significantly improved 5-year DFS and OS rates within stage III disease with statistically significant, (Figure 4 and Figure 5). Details for FIGO stage III are shown in table 2. Patients in FIGO stage I-Il, high and low initial CA 125 levels (cut-off $\geq 385 \mathrm{U} / \mathrm{ml}$ ) could not be found statistically significant in survival rates; 5-year DFS $(p=0.558)$ and 5-year OS $(p=0.935)$.

\section{DISCUSSION}

Prognosis of HGSC is not promising and the most lethal cancer in gynecologic cancers. In this study, pretreatment CA 125 levels were evaluated and set forth the prognostic importance in five-year survival rates for patients with HGSC. The patients were reviewed consecutively from two Oncology Clinics to avoid possible bias, and CA 125 levels were measured using the similar methods in two centres to synchronize laboratory data.

Previous studies emphasized the relationship between serum CA 125 levels and survival, but the results are contradictory. Juretzka et al. has studied the predictive value of CA 125 level during neoadjuvant chemotherapy; 241 patients, who were diagnosed with ovarian cancer and received intraperitoneal therapy following primary treatment, were included. The median follow-up time was 10 years. ${ }^{16}$ They stratified CA 125 levels after complete resection and adjuvant chemotherapy in three groups: $<10 \mathrm{U} / \mathrm{ml}, 11-20 \mathrm{U} / \mathrm{ml}$, and $21-30 \mathrm{U} / \mathrm{ml}$. OS was longer in patients with CA125 $\leq 12$
$\mathrm{U} / \mathrm{ml}$ (median 5.8 years) compared with $>12$ (median 3.7 years, $p=0.0027$ ). This study was focused on posttreatment CA 125 levels; and results showed that CA 125 levels could be clued to show recurrence. Predictive value of the pretreatment serum CA125 level for recurrence and overall survival rates were analysed in present study. Studies showed that both pre- and post-treatment CA 125 levels are important and could be predictive, if tumor is sensitive to CA 125 levels. Present study indicated that, patients of all stages included, with CA 125 values $<385 \mathrm{U} / \mathrm{ml}$ at the time of diagnosis had significantly better DFS ( $p<0.001$ ). Moreover, this cut-off value was also related to OS $(p=0.001)$.

The importance of baseline CA 125 levels as a predictive value for HGSC is reviewed by Bachmann R. and colleagues. ${ }^{17}$ They studied prognostic indicator of pretreatment serum CA125 in 261 HGSC patients. Patients were divided into two groups, a cut-off-level of $500 \mathrm{U} / \mathrm{ml}$ was chosen. patients with $\mathrm{CA} 125 \geq 500 \mathrm{U} / \mathrm{ml}$ group had worse DFS $(P=0.011)$ and OS $(P=0.023)$ compared with in the CA125 $<500 \mathrm{U} / \mathrm{ml}$ group. They suggested pretreatment CA 125 level in all FIGO stages appeared to be helpful in predicting suboptimal cytoreductive surgery for patients diagnosed with HGSC. Additionally, May et al., included 212 patients to study, and the initial CA 125 levels were measured $^{18}$; only patients who had received neoadjuvant chemotherapy were excluded from this study. ${ }^{18}$ All patients underwent surgery; preoperative CA125 cut-off level of 174 $\mathrm{U} / \mathrm{mL}$ was identified. $174 \mathrm{U} / \mathrm{mL} \leq$ levels of CA 125 were associated with worsened OS rates $(p<0.001)$. In this study, similar results were found with different cut-off level. Patients with CA 125 levels $\geq 385 \mathrm{U} / \mathrm{ml}$ had worsened survival rates than patients with CA 125 levels $<385 \mathrm{U} / \mathrm{ml}$ for all FIGO stages of HGSC. This analysis was statistically significant for both DFS and OS. OS with ( $\mathrm{HR}=3.13,95 \% \mathrm{Cl}$ : 1.53-6.41, p: 0.002) and DFS with $(\mathrm{HR}=2.35,95 \% \mathrm{Cl}$ : $1.51-3.64, p<0.001)$.

Rossi and colleagues studied preoperative CA 125 levels in 82 patients with ovarian cancer, and as a result, they determined preoperative CA 125 well correlated with the FIGO stage but not related to relapse of disease. ${ }^{19} A$ significant correlation between stage and CA 125 serum levels was determined in patients diagnosed at stage I and II. Contrary to that, no statistically significant relation was determined in patients diagnosed at stage III or IV. Nagele et al. investigated preoperative CA 125 levels at FIGO stage I patients and found patients with initial CA 125 levels $\geq 65 \mathrm{Um} / \mathrm{L}$ were associated with a decreased overall survival. ${ }^{20}$ But after excluding these patients, only 92 patients had been included survival analysis. The small sample size of patients may have caused bias. But this study highlighted the importance of initial CA 125 level in disease follow-up. Morales-Vásquez. et al. investigated pretreatment CA 125 level in all types of ovarian cancer patients as a predictive value. ${ }^{21}$ Patients with HGSC FIGO stage III showed survival difference with statis- 
tical significance. Patients were divided into two groups, according to CA 125 levels and cut-off value was chosen 500 $\mathrm{U} / \mathrm{mL}$ Pretreatment CA 125 levels higher than $500 \mathrm{U} / \mathrm{mL}$ group showed poor survival analysis than lower than 500 $\mathrm{U} / \mathrm{mL}$ group ( $p=0.032$ ). Present study's findings suggested that CA 125 levels were correlated with survival results within FIGO stage III patients; but the same statistical significance could not be shown in patients with FIGO stage I and II. The reason of this may be, in early stages of HGSC life expectancy is long and in this study follow-up time could be not enough.

Høgdall et al. investigated CA125 levels as a prognostic value for 382 women patients diagnosed with HGSC before surgery. ${ }^{22}$ They analysed the CA 125 expression in both tissue of tumor and blood sample of patients for determining of survival rates. A significant positive correlation was found between all FIGO stages and CA125 tissue expressions. Same statistically significance could not be seen between initial serum CA 125 level in and survival rates for all FIGO stages. In sub-group analysis only patients in FIGO stage III with initial serum CA 125 levels $<265.5 \mathrm{U} / \mathrm{ml}$ had improved DFS and OS ( $p<0.0001$ ). Vega et.al. designed a study with HGSC with all stages. ${ }^{23}$ They studied a predictive equation of metastases with pretreatment CA 125 level. They divided patients into two groups; first group included FIGO I-II, and second group was with FIGO stage III and IV. They calculated the cut-off point of the Ca-125 level to predict the presence of metastases in second study group was $240 \mathrm{u} / \mathrm{ml}$ with statistically significance $(P<0.001)$. In present study difference, patients in FIGO stage III with initial CA 125 levels $<385 \mathrm{U} / \mathrm{ml}$ had better OS than patients with $\geq 385 \mathrm{U} / \mathrm{ml}$ ( $p$ : 0.010).

Gupta et al. investigated preoperative CA 125 levels in advanced ovarian cancer to predict survival outcomes. ${ }^{24}$ Four hundred and thirty-five women with all sub types of epithelial ovarian cancer, FIGO stages III and IV were also included. As a result, preoperative CA-125 levels of $<100$ $\mathrm{U} / \mathrm{ml}$ were found to be statistically significant with better OS and PFS. This study was similar to this study's findings but, in present study, patients diagnosed with HGSC and FIGO stage I-II-III were included and excluded those diagnosed with FIGO stage IV. Both studies found similar results with different cut-off values. The present study excluded FIGO stage IV, this could be the reason of different cut-off values. Parashkevova and colleagues also studied preoperative CA 125 levels of serous ovarian cancer. ${ }^{25}$ They included both LGSCs and HGSCs; in subgroup analysis they found cut off value $164.5 \mathrm{U} / \mathrm{ml}$ especially significant for platinum sensitive HGSCs. These studies highlight of initial CA 125 level seemed to predictive value for ovarian cancer especially in HGSC. This study indicated that initial CA 125 level is an independent predictive of survival. In previous studies, investigators especially emphasized CA 125 as a prognostic tool. Additionally, present study advocates initial CA 125 level as predictive marker in HGSC, especially in FIGO stage III. Cut-off value of initial CA 125 was found $385 \mathrm{U} / \mathrm{ml}$. Patients with $<385 \mathrm{U} / \mathrm{ml}$ CA 125 levels were better survival rates than $\geq 385 \mathrm{U} / \mathrm{ml}$.

As in all studies, there are limitations in this analysis. Patients of present study were reviewed from two hospitals, and surgical operations were performed by different surgeons. In all the patients, surgery was optimal cytoreduction optimal, and no residual disease was detected. Also, this study is designed as retrospectively so further prospective designed studies are needed to support this data.

\section{CONCLUSION}

Based on the results of this study, it is concluded that the examination of baseline CA 125 levels may predict significant prognostic aspects among patients with HGSC. The pretreatment CA 125 level $<385 \mathrm{U} / \mathrm{ml}$ can advocate significantly better DFS, and OS and this cut-off value may predict a prognosis of the disease.

\section{ETHICAL APPROVAL:}

The study was conducted in accordance with the Declaration of Helsinki, and the protocol was approved by the Ethics Committee of The Institutional Review Board of Istanbul Medeniyet University Hospital Local Ethics Committee (IRB No. 2020/0014). That ethical approval was obtained prior to initiation of the present study.

\section{PATIENTS' CONSENT:}

This study was designed retrospectively, therefore getting the patient consent in person was not possible. For this reason, we applied to Ethical Committee of Medeniyet University by ensuring the patients' anonymity and protection of the patient data.

\section{CONFLICT OF INTEREST:}

The authors declared no conflict of interest.

\section{AUTHORS' CONTRIBUTION:}

SA: Substantial contributions to the conception or design of the work, or the acquisition, analysis, or interpretation of data for the work, drafting the work or revising it critically for important intellectual content.

DTO: Contributed to design articles and analysing data.

OD: Contributed to collecting and analysing data.

MB: Contributed to data collection, statistical analysis.

MEY, MG: Data analysis, drafting the work, revising it critically for important intellectual contents, and final approval.

\section{REFERENCES}

1. Arora T, Mullangi S, Lekkala MR. Ovarian Cancer. StatPearls. Treasure Island (FL)2021.

2. Doherty JA, Peres LC, Wang C, Way GP, Greene CS, Schildkraut JM. Challenges and opportunities in studying the epidemiology of ovarian cancer subtypes. Curr Epidemiol 
Rep 2017; 4(3):211-20. doi: 10.1007/s40471-017-0115-y.

3. Arora S, Balasubramaniam S, Zhang H, Berman T, Narayan P, Suzman D, et al. FDA approval summary: Olaparib monotherapy or in combination with bevacizumab for the maintenance treatment of patients with advanced ovarian cancer. Oncologist 2021; 26(1):e164-e72. doi: 10.1002/onco.13551.

4. Bast RC Jr, Hennessy B, Mills GB. The biology of ovarian cancer: New opportunities for translation. Nat Rev Cancer 2009; 9(6):415-28. doi: 10.1038/nrc2644.

5. Vaughan S, Coward JI, Bast RC Jr, Berchuck A, Berek JS, Brenton JD, et al. Rethinking ovarian cancer: Recommendations for improving outcomes. Nat Rev Cancer 2011; 11(10):719-25.

6. Gandhi T, Bhatt H. Cancer Antigen 125. StatPearls. Treasure Island (FL)2021.

7. Ahmad B, Nawaz S, Ali S, Bashir S, Mahmood N, Gul B. Level and evaluation of tumor marker CA-125 in ovarian cancer patients in Khyber Pakhtunkhwa, Pakistan. Asian Pac J Cancer Prev 2015; 16(1):185-9. doi: 10.7314/apjcp.2015. 16.1.185.

8. Fiala L, Bob P, Raboch J. Oncological markers CA-125, CA 19-9 and endometriosis. Med (Baltimore) 2018; 97(51): e13759. doi: 10.1097/MD.0000000000013759.

9. Salminen L, Nadeem N, Jain S, Grenman S, Carpen O, Hietanen $\mathrm{S}$, et al. A longitudinal analysis of CA125 glycoforms in the monitoring and follow up of high grade serous ovarian cancer. Gynecol Oncol 2020; 156(3):689-94. doi: 10.1016/j.ygyno.2019.12.025.

10. Piatek S, Panek G, Lewandowski Z, Bidzinski M, Piatek D, Kosinski $P$, et al. Rising serum CA-125 levels within the normal range is strongly associated recurrence risk and survival of ovarian cancer. J Ovarian Res 2020; 13(1):102. doi: 10.1186/s13048-020-00681-0.

11. Henderson JT, Webber EM, Sawaya GF. Screening for ovarian cancer: Updated evidence report and systematic review for the us preventive services task force. Jam 2018; 319(6):595-606. doi: 10.1001/jama.2017.21421.

12. Force USPST, Grossman DC, Curry SJ, Owens DK, Barry MJ, Davidson KW, et al. Screening for ovarian cancer: US Preventive services task force recommendation statement. Jama 2018; 319(6):588-94. doi: 10.1001/jama.2017.21926.

13. Nebgen DR, Lu KH, Bast RC Jr. Novel approaches to ovarian cancer screening. Curr Oncol Rep 2019; 21(8):75.

14. Prat J, Oncology FCoG. Staging classification for cancer of the ovary, fallopian tube, and peritoneum. Int J Gynaecol Obstet 2014; 124(1):1-5. doi: 10.1016/j.ijgo.2013.10.001.

15. Cho HY, Park SH, Park YH, Kim HB, Kang JB, Hong SH, et al. Comparison of HE4, CA125, and risk of ovarian malignancy algorithm in the prediction of ovarian cancer in Korean women. J Korean Med Sci 2015; 30(12):1777-83. doi: 10.3346/jkms.2015.30.12.1777.
16. Juretzka MM, Barakat RR, Chi DS, lasonos A, Dupont J, AbuRustum NR, et al. CA125 level as a predictor of progression-free survival and overall survival in ovarian cancer patients with surgically defined disease status prior to the initiation of intraperitoneal consolidation therapy. Gynecol Oncol 2007; 104(1):176-80. doi: 10.1016/j.ygyno.2006. 07.027 .

17. Bachmann R, Brucker S, Stabler A, Kramer B, Ladurner R, Konigsrainer $A$, et al. Prognostic relevance of high pretreatment CA125 levels in primary serous ovarian cancer. Mol Clin Oncol 2021; 14(1):8. doi: 10.3892/mco.2020.2170.

18. May T, Stewart JM, Bernardini MQ, Ferguson SE, Laframboise $\mathrm{S}$, Jiang $\mathrm{H}$, et al. The prognostic value of perioperative, pre-systemic therapy CA125 levels in patients with high-grade serous ovarian cancer. Int J Gynaecol Obstet 2018; 140(2):247-52. doi: 10.1002/ijgo.12376.

19. Rossi AC, Di Vagno G, Cormio G, Cazzolla A, Stefanelli S, D'Elia $\mathrm{E}$, et al. A retrospective study of preoperative CA 125 levels in 82 patients with ovarian cancer. Arch Gynecol Obstet 2004; 269(4):263-5. doi: 10.1007/s00404-0020404-6.

20. Nagele F, Petru E, Medl M, Kainz C, Graf AH, Sevelda P. Preoperative CA 125: An independent prognostic factor in patients with stage I epithelial ovarian cancer. Obstet Gynecol 1995; 86(2):259-64. doi: 10.1016/0029-7844(95) 00126-c.

21. Morales-Vasquez F, Pedernera E, Reynaga-Obregon J, LopezBasave HN, Gomora MJ, Carlon E, et al. High levels of pretreatment CA125 are associated to improved survival in high grade serous ovarian carcinoma. J Ovarian Res 2016; 9(1):41. doi: 10.1186/s13048-016-0247-6.

22. Hogdall EV, Christensen L, Kjaer SK, Blaakaer J, Kjaerbye-Thygesen A, Gayther S, et al. CA125 expression pattern, prognosis and correlation with serum CA125 in ovarian tumor patients. From The Danish "MALOVA" Ovarian Cancer Study. Gynecol Oncol 2007; 104(3):508-15. doi: 10.1016/j.ygyno.2006.09.028.

23. Sanchez Vega JF, Murillo Bacilio MDR, Vintimilla Condoy AS, Palta Gonzalez AM, Crespo Astudillo JA, Mora-Bravo FG. Predictive equation of metastasis in patients with malignant ovarian epithelial tumors with the Ca-125 marker. BMC Cancer 2018; 18(1):587. doi: 10.1186/s12885-018-4499-y.

24. Gupta M, Patel SM, Arora R, Tiwari R, Dave P, Desai A, et al. Does preoperative CA-125 cutoff value and percent reduction in CA-125 levels correlate with surgical and survival outcome after neoadjuvant chemotherapy in patients with advanced-stage ovarian cancer? - Our experience from a tertiary cancer institute. South Asian J Cancer 2020; 9(1):30-3. doi: 10.4103/sajc.sajc_53_17.

25. Muallem MZ, Parashkevova A, Almuheimid J, Richter R, Diab $\mathrm{Y}$, Braicu El, et al. Preoperative CA-125 values as a predictive factor for the postoperative outcome in primary serous ovarian cancer. Anticancer Res 2017; 37(6):3157-61. doi: 10.21873/anticanres.11674. 